\title{
Moving beyond mineral solubility: Physical and hydrologic constraints on $\operatorname{Cr}(\mathrm{VI})$ formation
}

\author{
Debra Hausladen, ${ }^{1}$ Sarah Fakhreddine, ${ }^{2}$ Scott \\ FENDORF $^{3}$ \\ ${ }^{1}$ Université de Sherbrooke, Department of Civil, \\ Environmental, and Building Engineering, Sherbrooke, \\ Québec,debra.hausladen@usherbrooke.ca \\ ${ }^{2}$ Bureau of Economic Geology, University of Texas at Austin, \\ Austin, TX,sarahfak@utexas.edu \\ ${ }^{3}$ Stanford University, Earth System Science Department, \\ Stanford,CA, fendorf@stanford.edu
}

Chromium(VI) produced from the oxidation of indigenous $\mathrm{Cr}$ (III) minerals is increasingly being recognized as a threat to groundwater quality. Predicting vulnerable environments, however, remains a challenge as groundwater $\mathrm{Cr}(\mathrm{VI})$ concentrations can vary greatly even within a given aquifer due to physical and hydrologic heterogeneity. A critical determinant of $\mathrm{Cr}(\mathrm{VI})$ generation within soils and sediments is the necessary interaction of two low solubility phases that lead to its production: $\mathrm{Cr}(\mathrm{III})$ silicates or (hydr)oxides and Mn(III/IV) oxides. However, it remains unknown to what extent the physical structure of soils may control $\mathrm{Cr}(\mathrm{VI})$ production by dictating the separation distance between reactive phases, determing the diffusion distance from $\mathrm{Cr}(\mathrm{VI})$ generation sites to advecting groundwater, or regulating infiltration rates and porewater velocity. In this study, we use a dual-pore domain model to investigate the relative control of these parameters, together with $\mathrm{Cr}$-mineral solubility. Indeed, the reaction distance between $\mathrm{Cr}(\mathrm{III})$ bearing minerals and $\mathrm{Mn}$ oxides predominantly controls $\mathrm{Cr}(\mathrm{VI})$ export to advecting groundwater. Changes in diffusion distance between sites of $\mathrm{Cr}(\mathrm{VI})$ generation and advective flow channels has little impact on steady-state $\mathrm{Cr}(\mathrm{VI})$ concentrations, but long diffusion distances may suppress $\mathrm{Cr}(\mathrm{VI})$ transport under fluctuating hydrologic and biogeochemical conditions by increasing the time required for groundwater $\mathrm{Cr}(\mathrm{VI})$ concentrations to reach steady-state. Finally, we show that high porewater flow velocities effectively dilute $\mathrm{Cr}(\mathrm{VI})$ diffusing from soil/sediment aggregates, thus minimizing $\mathrm{Cr}(\mathrm{VI})$ export relative to lower porewater velocities. In combination, our results recommend consideration of factors beyond $\mathrm{Cr}$ (III)-mineral solubility when predicting $\mathrm{Cr}(\mathrm{VI})$ production within soils and sediments. Physical and hydrologic controls on $\mathrm{Cr}(\mathrm{VI})$ production appear to be capable of overwhelming the impact of $\mathrm{Cr}(\mathrm{III})$-mineral solubility in soils and sediments. 